\title{
Analysis of Genital Tract Malignancies in Postmenopausal Indian Women
}

\author{
Savita A Somalwar, Sulabha Joshi, Anjali Kawthalkar, Anuja Bhalerao, Sheela Jain, Ashutosh Somalwar
}

\section{ABSTRACT}

Introduction: Genital malignancies in women varies widely from developed to developing countries. Postmenopausal women are at risk of developing various genital malignancies.

Objectives: (1) To determine frequency of genital tract malignancies in postmenopausal women, (2) to determine the type and stage of genital tract malignancies, (3) to create awareness of screening in women.

Materials and methods: This descriptive cross-sectional study was carried out over a period of 2 years from March 2010 to Feb. 2012. It included 200 postmenopausal women admitted with complaints like mass or fullness of abdomen, bleeding or discharge per vaginal and ulcer over vulva. They were evaluated clinically followed by relevant investigations. Malignancy was confirmed by histopathology report.

Results: Out of 200 postmenopausal women admitted during study period, malignancy was confirmed in 55 women (27.5\%). The type of malignancy was cervical carcinoma $(30,54.54 \%)$, ovarian carcinoma $(18,32.72 \%)$, carcinoma endometrium $(5,9.09 \%)$, carcinoma vulva $(1,1.81 \%)$ and carcinoma vagina $(1,1.81 \%)$. Majority of carcinoma cervix and ovarian carcinoma were in advanced stage.

Conclusion: Carcinoma cervix was commonest genital malignancy found our study followed by carcinoma ovary. Importance of routine gynecological check-up in postmenopausal women was emphasised.

Keywords: Postmenopausal, Malignancy, Carcinoma.

How to cite this article: Somalwar SA, Joshi S, Kawthalkar A, Bhalerao A, Jain S, Somalwar A. Analysis of Genital Tract Malignancies in Postmenopausal Indian Women. J South Asian Feder Menopause Soc 2013;1(2):66-69.

Source of support: Nil

Conflict of interest: None declared

\section{INTRODUCTION}

In this era, life expectancy has increased, so more number of women will experience postmenopausal period. Life expectancy is now 82 years for a woman living in the UK and more than $30 \%$ of women are aged 50 or above. ${ }^{1}$ These women therefore will live $1 / 3 \mathrm{rd}$ of their lives in postmenopausal state.

Genital tract malignancies constitute about $14 \%$ of cancers in women. ${ }^{2}$ Ovarian, endometrial and vulvar cancers tend to occur primarily in postmenopausal women. Nearly 75,000 new pelvic malignancies, involving the endometrium ovary, cervix, vagina, vulva tubes as well as gestational trophoblastic disease and pelvic sarcomas are being diagnosed every year.

\section{MATERIALS AND METHODS}

This descriptive cross sectional study was carried out over a period of 2 years from March 2010-Feb. 2012 at NKP Salve Institute of Medical Sciences and Lata Mangeshkar Hospital, Nagpur, Maharashtra, India, which is a tertiary care center catering rural population. Institutional ethical committee approval was taken.

Study included 200 postmenopausal women admitted in gynecology ward.

\section{Inclusion Criteria}

1. Postmenopausal women admitted in gynecology ward with clinical features suggestive of genital tract malignancy like mass or fullness of abdomen, bleeding per vaginam, discharge per vaginam and ulcer over vulva, etc.

\section{Exclusion Criteria}

1. Postmenopausal women with urinary complaints.

2. Postmenopausal women with mass coming out of vagina without postmenopausal bleeding or nonhealing decubitus ulcer.

\section{METHODS}

History was taken in detail, followed by thorough clinical examination and relevant investigations. Women were managed according to diagnosis and stage of malignancy. Malignancy was confirmed from histopathology report. Analysis of data was done with respect to age, parity, type of malignancy, stage of malignancy and frequency of each type of malignancy. The chi-square test was applied to calculate the age distribution of malignancies.

\section{OBSERVATIONS AND RESULTS}

A total of 200 postmenopausal women were admitted during study period from March 2010 to Feb 2012.

Majority of women were in age group $<60$ years $(\mathrm{p}=0.0069)($ Table 1$)$.

Out of 200 women, 55 had genital tract malignancies $(27.5 \%)$. Out of 55 women 30 had carcinoma cervix (54.54\%). Out of 30 women with carcinoma cervix 29 were in advanced stage, i.e. Stage III B and only 1 was in early stage, i.e. stage II A. Women with advanced stage were 


\begin{tabular}{llllll}
\hline \multicolumn{5}{c}{ Table 1: Age group of women along with } \\
type of malignancy
\end{tabular}

Table 2: Type of genital tract malignancy in postmenopausal women

\begin{tabular}{lll}
\hline Malignancy & No. (55) & Percentage \\
\hline Carcinoma cervix & 30 & 54.54 \\
Carcinoma ovary & 18 & 37.72 \\
Carcinoma endometrium & 5 & 9.09 \\
Carcinoma vulva & 1 & 1.8 \\
Carcinoma vagina & 1 & 1.8 \\
\hline
\end{tabular}

Table 3: Relationship of parity with type of malignancy

\begin{tabular}{llll}
\hline Malignancy & \multicolumn{3}{c}{ Parity } \\
\cline { 2 - 4 } & Nullipara & $<3$ & $>3$ \\
\hline Carcinoma cervix & - & 2 & 28 \\
Carcinoma ovary & 12 & 6 & - \\
Carcinoma endometrium & 3 & 2 & - \\
Carcinoma vulva & - & 1 & - \\
Carcinoma vagina & - & 1 & - \\
\hline
\end{tabular}

Table 4: Stages of malignancy

\begin{tabular}{lll}
\hline Malignancy & Stages & No. of women \\
\hline Carcinoma of cervix & IIA & 1 \\
Carcinoma ovary & IIIB & 29 \\
& IB & 5 \\
& IIA & 2 \\
IIIA & 8 \\
Carcinoma endometrium & IIIB & 3 \\
Carcinoma vulva & IA & 2 \\
Carcinoma vagina & II & 3 \\
\hline
\end{tabular}

Table 5: Comparing the frequency of malignancies in various studies with present study

\begin{tabular}{llllllc}
\hline Study & Year & $\begin{array}{l}\text { Carcinoma } \\
\text { cervix (\%) }\end{array}$ & $\begin{array}{l}\text { Carcinoma } \\
\text { endometrium (\%) }\end{array}$ & $\begin{array}{l}\text { Carcinoma } \\
\text { ovary (\%) }\end{array}$ & $\begin{array}{l}\text { Carcinoma } \\
\text { vulva (\%) }\end{array}$ & $\begin{array}{l}\text { Carcinoma } \\
\text { vagina (\%) }\end{array}$ \\
\hline Banerjee MS and Halder B & 1976 & 10 & 3.20 & 0.40 & 0.40 & 0.40 \\
Bhargav A and Pant & 1982 & 71.43 & 16.33 & 9.52 & - & 2.37 \\
Sengupta A et al & 1990 & 32 & 8 & 2 & - & - \\
Arora R et al & 1992 & 75.89 & 5.35 & 11.67 & 5.35 & 1.78 \\
Debnath S et al & 1994 & 42.80 & 1 & 3 & 0.80 & 0.40 \\
Naik VS et al & 2004 & 39.42 & 9.61 & - & - & - \\
Kauser Jillani et al & 2010 & 14 & 8 & 16.17 & 7.35 & 2.94 \\
Farkhunda K et al & 2010 & 60.28 & 11.76 & 37.72 & 1.81 & 1.81 \\
Present study & 2012 & 54.54 & 9.09 & & & \\
\hline
\end{tabular}

referred for radiotherapy while one woman with early stage underwent Wertheim's Hysterectomy.

Eighteen women out of 55 (37.52 \%) had ovarian malignancy. Ovarian malignancy was second most common malignancy found in our study. All women had advanced stage malignancy and received chemotherapy postoperatively after staging laparotomy.

Endometrial carcinoma was detected in 5 women $(9.09 \%)$. These women underwent surgery and it was stage IB in 3 women. These women were advised postoperative pelvic radiotherapy as well as vault radiotherapy.

Vulval carcinoma was found in 1 woman (1.81\%) which was Stage II and was managed by radical vulvectomy with bilateral groin lymph node dissection. She was advised postoperative radiotherapy as lymph nodes were positive.

One woman had vaginal carcinoma (1.81\%) which was advanced stage, i.e. Stage III and hence she was advised radiotherapy (Tables 2 and 4 ).
Carcinoma cervix was found mostly in women who were 3 para and above. Carcinoma ovary was detected mostly in nulliparous women (Table 3).

None of the women were aware about screening and routine gynecology check-up.

\section{DISCUSSION}

Malignancy rate in postmenopausal women varies from country to country. ${ }^{3}$ Developing countries have a higher incidence because of lack of education and awareness.

In this study the frequency of malignancy was $27.5 \%$ in postmenopausal women, which is high as the study is carried out in a tertiary care center which caters rural population. Farkunda Khurseed et $\mathrm{al}^{4}$ reported frequency of malignancy as $25.66 \%$. Arora et $\mathrm{al}^{5}$ reported frequency of genital tract malignancies in $44.94 \%$ of women.

Carcinoma cervix was the most common malignancy found in our study, i.e. $54.54 \%$. Cervical cancer is a common 
cancer in women all over world and it is said to be the second most common tumor in women. ${ }^{6}$ Bhargava $\mathrm{H}$ and Pant $\mathrm{N}^{7}$ reported incidence of cancer cervix as $71.43 \%$. Sengupta A et $\mathrm{al}^{8}$ reported frequency of cancer cervix as $32 \%$ in their study. Arora $\mathrm{R}$ et $\mathrm{al}^{5}$ reported carcinoma cervix in $75.89 \%$ of women, while Debnath $\mathrm{S}$ et $\mathrm{al}^{9}$ reported incidence of carcinoma cervix as $42 \%$. Farkhunda $\mathrm{K}$ et $\mathrm{al}^{4}$ found cervical cancer in $60.28 \%$ of women in their study. Veena S Naik et $\mathrm{al}^{10}$ reported frequency of carcinoma cervix in $39.72 \%$ of women. Kauser Jillani et $\mathrm{al}^{11}$ reported incidence of carcinoma cervix as $14 \%$.

However in developed nations after introduction of cervical screening program, incidence of cervical cancer has shown a dramatic decline because of detection of disease at preinvasive stage. A significantly reduced incidence was reported in Finland, Iceland and Sweden. ${ }^{12}$ Australia now has the lowest incidence and mortality rate for cervical cancer worldwide. ${ }^{13}$ About $80 \%$ of all cases of cervical cancer annually occur in developing countries where only $5 \%$ of the female population had a pop smear within 5 years. ${ }^{3}$

Ovarian carcinoma was the second most malignancy found in our study with frequency of $37.72 \%$. Farkunda K et $\mathrm{al}^{4}$ reported carcinoma ovary as $16.17 \%$. Arora $\mathrm{R}$ et $\mathrm{al}^{5}$ found carcinoma ovary in $11.67 \%$ of women. $9.52 \%$ of women had carcinoma ovary in study by Bhargava $\mathrm{H}$ et al. ${ }^{7}$ Frequency of ovarian carcinoma reported by Sengupta et $\mathrm{al}^{8}$ as 2 and $3 \%$ by Debnath $\mathrm{S}$ et al. ${ }^{9}$ Ovarian cancer is the most frequent cause of death from gynecological malignancies in western world. ${ }^{14}$

The current life time risk is 1 per 48 . The incidence is approximately 22 per 10000 population peaking at the age of 67 years. ${ }^{15}$ In our study most cases were found between 55 and 60 years of age.

Endometrial carcinoma contributed to $9.09 \%$ of women which closely correlates with study by Naik VS et al. ${ }^{10}$ The frequency of carcinoma endometrium reported by other authors was $16.33 \%$ by Bhargava $\mathrm{H}$ et al, ${ }^{7} 11.76 \%$ by Ferkunda K et al, ${ }^{4} 8 \%$ by Sengupta A et al, ${ }^{8} 5.35 \%$ by Arora $\mathrm{R}$ et $\mathrm{al}^{5}{ }^{5} 3.20 \%$ by Banerjee MS et $\mathrm{al}^{20}$ and $1 \%$ by Debnath S et al. ${ }^{9}$

Endometrial carcinoma is the most common malignancy in women in western world where the life time risk of a women to develop endometrial carcinoma is $2 \%{ }^{2}$ Postmenopausal bleeding is an alarming sign of this malignancy and the incidence increases with delay in presentation of this symptom. The frequency of this malignancy with postmenopausal bleeding is reported to be $20.5 \% .{ }^{16}$ There is no good screening test for endometrial carcinoma. However, transvaginal ultrasound to detect endometrial thickness ${ }^{17}$ and measurement of endometrial volume $e^{18}$ can be used to predict malignancy. The peak age of endometrial carcinoma is between 56 to 65 years. ${ }^{10}$ In our study, carcinoma endometrium was seen between 61 and 70 years.

Vulval carcinoma is a rare disease accounting for $6 \%$ of gynecological malignancies and $1 \%$ of all cancers in women with an incidence rate of 1.7/100.000. The incidence varies considerably among investigators from 3 to $11 \%$. Vulval carcinoma was found in $1.81 \%$ in our study. The frequency of vulval carcinoma reported by various authors was $7.35 \%$ by Farkunda $\mathrm{K}$ et $\mathrm{al}^{4} 5.35 \%$ by Arora $\mathrm{R}$ et $\mathrm{al},{ }^{5} 0.8 \%$ by Debnath $\mathrm{S}$ et al, ${ }^{9} 0.4 \%$ by Banerjee MS et al. ${ }^{20}$ Vulval carcinoma should be a disease which is easily diagnosed because it is a essentially a skin malignancy apparent to vulval inspection very frequently the diagnosis of these malignancies is delayed because of delay on the part of patient as well as physician.

Vaginal carcinoma contributed to $1.81 \%$ in our study. It is rare malignancy. The peak incidence of this tumor is 6th decade of life ${ }^{19}$ which was also observed in our study (Table 5).

\section{CONCLUSION AND SUMMARY}

High frequency of malignancy was detected in our study (27.5\%). Commonest genital tract malignancy is carcinoma cervix in developing countries which was also found in our study. Carcinoma cervix was followed by ovarian carcinoma, endometrial carcinoma, vulval and vaginal carcinoma. Most of cervical and ovarian carcinomas were in advanced stage. Most malignancies were found in women $<60$ years. It is sad that although cervix is accessible for screening, carcinoma cervix is detected late because of ineffectiveness of existing surveillance and illiteracy in women. There is a need for aggressive education of doctors in rural areas as well as public education programs in rural areas, so that it will help to detect disease in precancerous stage. The importance of routine gynecological checkup in postmenopausal women should be emphasised so that premalignant lesions and malignancies can be detected and treated in early stages. Community education of women in the form of screening as well as early warning symptoms of malignancy is essential for prevention and early detection of malignancies. Opportunistic screening should be done whenever women visits hospital for any complaint. These women with malignancy were advised to spread the message of screening to their relatives, friends and neighbors. More studies on genital malignancies will be helpful in formulating guidelines for screening in Indian postmenopausal women. 


\section{ACKNOWLEDGMENT}

Unit Heads of all units of Obstetrics and Gynecology and Pathology Department of NKP. Salve Institute of Medical Sciences and Research and Lata Mangeshkar Hospital, Nagpur.

\section{REFERENCES}

1. Panay N. Menopause and postmenopausal women. In: Dewhurst's Textbook of Obstetrics and Gynaecology. 7th ed. UK: Blackwell Publishing; 2007. p. 479-495.

2. Guy I, Benrubi MD. Pelvic malignancies. Available at: www.demonline.org/jax_medicine/1999 Journals/January 99/ Pelvicmelig.htm.

3. Ergete W, Tesfaye A. Histopathological finding of postmenopausal bleeding in Ethiopian women. Ethiop J Health Dev 2001;15(1):39-44.

4. Khursheed F, Jatoi N, Das CM. Genital tract malignancies in postmenopausal women. J Ayub Med Coll Abbottabad 2010;22(3):32-34.

5. Arora R, et al. Pattern of Gynaecological problems in elderly women $(>60)$ in tertiary hospital-Journal of Gynaecology and Obstetrics of India 1992;42(1):86-89.

6. Shafi MI. Premalignant and malignant disease of cervix. In: Dewhurst's Book of Obstetrics and Gynaecology. 7th ed. Blackwell Publishing; 2007;614-624.

7. Bhargava H, Pant N. Journal of Obstetrics and Gynaecology of India 1992;32:436.

8. Sengupta A, et al. A study of 50 cases of postmenopausal bleeding. 1990 Aug;40(4):577-581.

9. Debnath $\mathrm{S}$, Geeta R, et al. Study of gynaecological problems in postmenopausal women. Journal of Obstetrics and Gynaecology of India 1994 April;44(2):286-289.

10. Naik VS, Rege JD, Jasnani KD. Pathology of genital tract in postmenopausal bleeding. Bombay Hospital Journal, 2005. Available at: www.bhj.org/journal/2005_4703_july/html/ original_pathology_250.htm.

11. Jillani K, Khero RB, Maqsood S, Siddiqui MA. Prevalence of malignant disorders in 50 cases of postmenopausal bleeding. JPMA (Journal of Pakistan Medical Association) July 2010.

12. Khan A, Soumro N, Bibi A. Screening for cervical cancer. Cytology or visual inspection. Med Channel 2001;7(2):1-3.

13. Blomfield P. Management of cervical cancer. Aust Fam Physician 2007;36(3):122-125.

14. Nugent D, Salha O, Bales AH, Rutherford AJ. Ovarian neoplasia and subfertility treatments. Br J Obstet Gynaecol 1998;105: 584-601.

15. Gabra H. Epithelial ovarian cancer. In: Deuhurst's book of obstetrics and gynaecology. 7th ed. UK: Blackwell Publishing 2007. p. 625-635.

16. Asim SS, Akthar AZ. Frequency of malignancy in women presenting with postmenopausal bleeding. Ann Abbasi Shahid Hosp Karachi Med Dent Coll 2004;9:506-509.
17. Epestein E, Valentin L. Rebleeding and endometrial growth in women with postmenopausal bleeding and endometrial thickness less than $5 \mathrm{~mm}$ managed by dilation and curratage or ultrasound follow-up: a randomized controlled study. Ultrasound Obstet Gynaecol 2001;18:499-504.

18. Mansur GM, El-Lamie IK, El-Kady NA, EL-Mekkavi SF, Laban M, Abou-Gabal AI. Endometrial volume as predictor of malignancy in women with postmenopausal bleeding. Int $\mathrm{J}$ Gynaecol Obstet 2007;99(3):206-210.

19. Luesly DM. Malignant disease of vulva and vagina. In: Deuhurst's book of obstetrics and gynaecology, 7th ed. UK: Blackwell Publishing; 2007. p. 591-605.

20. Banerjee MS, Halder B. Geriatric problems in Gynaecology. In Journal of Obstetrics and Gynaecology of India 1976;26: 262-267.

\section{ABOUT THE AUTHORS}

\section{Savita A Somalwar}

Lecturer, Department of Obstetrics and Gynecology, NKP Salve Institute of Medical Sciences and Lata Mangeshkar Hospital, Nagpur Maharashtra, India

Correspondence Address: Plot No. 264, Bajaj Nagar, West High Court Road, Nagpur-440010, Maharashtra, India, Phones: (Res.) 0712-2233167 (Off.) 07104-236290,(Mob.)9158920941, e-mail: somalwar.sa@gmail.com

\section{Sulabha Joshi}

Professor and Head, Department of Obstetrics and Gynecology, NKP Salve Institute of Medical Sciences and Lata Mangeshkar Hospital Nagpur, Maharashtra, India

\section{Anjali Kawthalkar}

Associate Professor, Department of Obstetrics and Gynecology, NKP Salve Institute of Medical Sciences and Lata Mangeshkar Hospital Nagpur, Maharashtra, India

\section{Anuja Bhalerao}

Associate Professor, Department of Obstetrics and Gynecology, NKP Salve Institute of Medical Sciences and Lata Mangeshkar Hospital Nagpur, Maharashtra, India

\section{Sheela Jain}

Assistant Lecturer, Department of Obstetrics and Gynecology, NKP Salve Institute of Medical Sciences and Lata Mangeshkar Hospital Nagpur, Maharashtra, India

\section{Ashutosh Somalwar}

Associate Professor, Department of Medicine, Government Medical College, Nagpur, Maharashtra, India 